\title{
FALSAS MEMÓRIAS NO PROCESSO PENAL: A INCIDÊNCIA DE FALSAS MEMÓRIAS NA PROVA TESTEMUNHAL
}

\author{
FALSE MEMORIES IN THE CRIMINAL PROCEDURE: THE \\ INCIDENCE OF FALSE MEMORIES IN THE TESTIMONY
}

\section{FÁBIO ANDRÉ GUARAGNI}

Doutor e Mestre em Direito das Relações Sociais pela UFPR, com pesquisa pósdoutoral junto à Università degli Studi di Milano. Professor de Direito Penal Econômico do PPGD (Doutorado e Mestrado) do Centro Universitário Curitiba Unicuritiba. Professor de Direito Penal da graduação e pós-graduação lato sensu -no Unicuritiba, Fundação Escola do Ministério Público do Paraná, Escola da Magistratura Estadual do Paraná e Escola da Magistratura Federal do Paraná. Procurador de Justiça junto ao Ministério Público do Estado do Paraná.

\section{CAROLINE MAYUMI TANAKA}

Pós-Graduada em Direito Aplicado pela Escola da Magistratura do Paraná ESMAE.

\section{RESUMO}

Objetivo: O objetivo do estudo é compreender a capacidade da mente humana de criar falsas memórias e sua influência e incidência na prova testemunhal do processo penal. Aponta para a alta incidência de casos de falsas memórias no processo penal brasileiro.

Metodologia: A partir de pesquisa documental, utiliza o método dedutivo para, valendo-se de textos doutrinários, legislativos, jurisprudenciais e constitucionais, extrair conclusões sobre a as falas memórias em depoimentos. 
Resultado: Apresentam-se algumas medidas capazes de diminuir a presença de falsas memórias em testemunhos durante a instrução, de maneira a minimizar o impacto negativo, na resolução dos casos penais, destas falhas cognitivas usuais que caracterizam os processos mnemônicos.

Contribuições: $O$ reconhecimento da relevância do trabalho multidisciplinar nos estudos das falsas memórias, na capacitação dos profissionais de Direito acerca deste aspecto e na integração de profissionais de outras áreas no ambiente do processo criminal.

Palavras-chave: Processo penal; prova testemunhal; falsas memórias.

\section{ABSTRACT}

Objective: The objective of the study is to understand the capacity of the human mind to create false memories and its influence and impact on the testimonial evidence of the criminal process. It points to the high incidence of cases of false memories in the Brazilian criminal process.

Methodology: Based on documentary research, it is used the deductive method to, based on doctrinal, legislative, jurisprudential and constitutional texts, obtain conclusions about the false memories in testimonies.

Result: Some measures are presented to reduce the presence of false memories in testimonies during instruction, in order to minimize the negative impact in the resolution of criminal cases of these usual cognitive flaws that characterize mnemonic processes.

Contributions: Recognition of the relevance of multidisciplinary work in the study of false memories, in the training of legal professionals about this aspect and in the integration of professionals from other areas in the criminal process environment.

Keywords: Criminal procedure; testimonial evidence; false memories. 


\section{INTRODUÇÃO}

A prova é o meio hábil para as partes evidenciarem a veracidade dos fatos alegados no curso do debate processual, de modo a formar o convencimento do juiz. Conduzem à adequada recognição das questões de fato subjacentes à discussão processual. Sabe-se que não se atinge, através do processo, uma dada verdade real (LOPES JR., 2015, p.193-194). A recognição dos fatos pauta-se pela maximização da verossimilhança entre o fato histórico e sua reconstrução. Uma inadequada identificação da quaestio facti impede, de partida, a tomada de decisões justas, seja pela pura e simples reconstrução falha dos eventos, seja porque a hipótese de fato mal firmada conduz à incidência equivocada das regras jurídicas.

Dentre os diversos tipos de prova, a testemunhal assume imensa relevância no processo penal, convertendo-o em eventual cenário de confusões que o indivíduo pode produzir ao reviver as lembranças do crime e suas circunstâncias. As falsas memórias na prova testemunhal derivam de diversos fatores internos e externos, vivências e percepções que influenciam diretamente naquilo que vemos, ouvimos e interpretamos. Em muitas situações, enfraquecem a qualidade da prova.

Este é um tema caro à justiça penal, por afetar toda a condução de um processo ou julgamento, e muito complexo, por envolver diversas disciplinas. Exige que profissionais e operadores do direito expandam seus conhecimentos na direção de uma melhor compreensão acerca do funcionamento da mente humana.

Pressuposta a alta dependência que a justiça criminal possui em relação aos relatos de testemunhas ou informantes, bem como dos interrogatórios de imputados (meios diretos de defesa com proveito evidente na recognição fática), compreender como as falsas memórias influenciam nas decisões jurídicas é fundamental para os atos de gestão da prova oral - em particular, aqueles ligados à admissão e produção da prova. A adequada noção acerca das falsas memórias interfere, também, no momento da valoração da prova, no ambiente dos processos criminais. 
Por tudo, justifica-se o estudo do tema. Neste contexto, exploram-se os processos que levam a mente humana a criar falsas memórias, bem assim a respectiva repercussão na prova oral do processo penal.

\section{A PROVA NO PROCESSO PENAL: SEU OBJETO E A PROVA TESTEMUNHAL ENQUANTO MODALIDADE}

Com brevidade, fincam-se aqui dois pressupostos. Primeiro, uma rápida posição sobre o objeto da prova. Após, como a prova testemunhal internaliza-se no universo classificatório dos meios de prova.

\subsection{O OBJETO DA PROVA}

De modo inicial, pode-se dizer que a prova apresenta-se no processo como um instrumento para a busca da verdade. Isto suscita imediato questionamento acerca de qual verdade se busca.

Existem variadas concepções de verdade, desde a aristotélica noção de adequação do intelecto à coisa (verdade como ontologia dos objetos existentes no mundo), passando pela verdade como ideia humana lançada sobre o mundo, de raiz platônica e bem assentada, na modernidade, a partir da filosofia da consciência de corte kantiano (verdade como projeção de mundo do sujeito cognoscente).

No século $X X$, emergem novas concepções de verdade. Por exemplo, dá-se com Heidegger a percepção de que o homem, sujeito cognoscente, é ser-no-mundo e parte do objeto que quer conhecer, em vez de sujeito distanciado do mundo de objetos a serem conhecidos. A superação heideggeriana do dualismo sujeito-objeto da epistemologia tradicional, mediante a fenomenologia, deu-se "do mundo que se revela e da consciência, desde sempre relacionada com o mundo" (SAFRANSKI, 2005, p. 115). 
Também avulta o giro linguístico, concebendo a verdade enquanto consenso entre agentes comunicantes, exaltando o universo de sentido criado pela linguagem, para o qual os objetos de mundo são meros substratos.

A verdade atingível no processo, sob este olhar, dá-se como "argumentação intersubjetiva, comunicável linguisticamente, e racionalmente verificável das razões pelas quais se chegou a uma determinada valoração e, pois, a uma decisão", de modo a que não se pode atingir verdades absolutas, mas apenas aquela que "induvidosa e intersubjetivamente possa dar-se por provada" (MUÑOS CONDE, 2003, pp. 115 e 117), dentro dos limites procedimentais, sobretudo aqueles alusivos ao recolhimento da prova.

O que se colhe, certamente, é a impossibilidade de certa verdade real ou certeza absoluta (BADARÓ, 2003, p. 31), cuja busca foi, por muito tempo, orientação de princípio processual penal. $O$ jogo argumentativo procedimental relativiza o olhar com que se reconstroem os fatos, diante de outros interesses que também compõem as pretensões do processo - com destaque para aqueles que, no cinturão de garantias processuais, respondem pela vedação de excesso em face do réu -, restando obter, através da instrução, mera "constatação empírica parcial" (VOLK, 2007, p. 102).

O objetivo da parte, dentro do processo penal, é convencer o magistrado de que a sua noção da realidade é a correta, de que os fatos deram-se da maneira sustentada, à revelia da narrativa do adversário. Aduz Greco Filho (2015, p.212) que "a finalidade da prova é o convencimento do juiz [...]. Não se busca a certeza absoluta, a qual, aliás, é sempre impossível, mas a certeza relativa suficiente na convicção do magistrado."

Com base nos ensinamentos de Cristina Di Gesu (2014, p. 6), o determinante no sistema acusatório é a busca, pelas partes, do convencimento do julgador, fato este que desencadeia a função eminentemente persuasiva da prova, desenvolvida dentro de um quadro de princípios. Obtém-se a verdade possível a partir do jogo procedimental. São ao menos três os princípios processuais penais que norteiam a prova, quais sejam: a) o princípio da investigação, orientado pela 
ideia de que o juiz só poderá manifestar a sua decisão mediante os fatos alegados pelas partes e as provas por elas produzidas; b) o princípio da livre apreciação da prova, que aponta para uma apreciação discricionária por parte do magistrado, porém sempre de maneira motivada; c) o princípio in dubio pro reo, que afirma, em síntese, que se houver dúvida acerca dos fatos é preferível a absolvição de um culpado do que a condenação de um inocente (FIGUEIREDO DIAS, 1974, p.115118).

Tais princípios cercam sobretudo a atividade judicial de valoração da prova, no ato sentencial, cujo convencimento a prova tem por objeto orientar.

\subsection{A CLASSIFICAÇÃO DA PROVA COMO TESTEMUNHAL}

São diversos os modos de catalogar a prova no processo penal, segundo variem os critérios. Exemplificativamente, podem ser diretas, quando demonstrarem o fato probando, ou indiretas, quando demonstram fatos diversos do thema probandum, a seu turno relacionados com o fato principal. Aqui, o critério é o vínculo do objeto de demonstração com o fato imputado. Quanto à força valorativa, diz-se plena a prova quando convincente para formação de um juízo ou indiciária, nãoplena, quando traz apenas probabilidades. (exemplificativamente, FEITOZA, 2009, p. 691/692) Quanto à forma pela qual é apresentada ao juízo, a prova classifica-se como documental, material ou testemunhal (LIMA, 2011, p. 842). Esta última é o tema de estudo.

De fato, a prova testemunhal configura-se como um forma de produção da prova. É aquela resultante do depoimento prestado por um sujeito estranho ao processo, acerca dos fatos relacionados ao caso penal.

Para a muitos autores brasileiros (LIMA, 2008, p.73; LOPES JR., 2013, p.481/482; CAPEZ, 2016, p. 471/472), a prova testemunhal possui três características fundamentais: a) oralidade, pois o depoimento será prestado oralmente, não sendo permitido trazê-lo por escrito; b) objetividade, porque a testemunha fala apenas sobre os fatos percebidos, sem emitir opiniões pessoais; c) 
retrospectividade, a significar que a testemunha se refere a fatos ocorridos no passado.

Estas usuais características mereceriam debates à parte, de menor ou maior monta. Quanto à primeira, por exemplo, note-se que o art. 204, parágrafo único, CPP, permite a consulta de apontamentos escritos. Da segunda, a partir da já aludida quebra heideggeriana do distanciamento entre sujeito cognoscente e objeto conhecido na compreensão de como se constitui a verdade sobre algo - eis que o agente é ser-no-mundo -, a pura objetividade torna-se inviável. O modo como se narra um fato vem impregnado de certa visão de mundo prévia ao narrador, e constitutiva de sua maneira de narrar. $\mathrm{E}$ o fato que narra pertence a um universo a que também ele, narrador, pertence. Isto frustra, em boa medida, a pretensão de objetivação da prova testemunhal.

A retrospecção, a sua vez, caracteriza a prova oral como caminho de volta em relação às suas fases formativas. Nas palavras de Aquino (1995, p.26-55), o testemunho possui três fases em sua formação, quais sejam: a) o conhecimento do fato, b) a conservação do conhecimento e c) a declaração do conhecimento. A primeira fase refere-se a apreensão, que é o momento em que ocorre o primeiro contato, a tomada do fato. A segunda fase, a conservação do conhecimento, se dá através de um processo de fixação, que depende diretamente da memória do indivíduo. E por fim, a terceira fase, na qual a testemunha transmite o seu conhecimento para a autoridade competente, completando, desta forma, o testemunho.

A testemunha, portanto, é peça fundamental no Processo Penal. Porém, a qualidade do seu relato depende de um conjunto de situações complexas. Por exemplo, o modo como dá sentido aos fragmentos de momentos que vivenciou, observou ou dos quais teve conhecimento, considerada a capacidade e limites da sua memória. Os filtros pelos quais o processo mnemônico ocorre interferem na construção do relato realizado após o lapso temporal transcorrido desde a vivência do quanto testemunhou (ROSA, 2014, p. s/n). Por isso, a palavra da testemunha, muitas vezes, não é suficiente para reconstruir a dinâmica dos fatos como 
exatamente ocorreram. Dão-se distorções quanto às imagens da "realidade" enquanto vivência.

É nesse contexto que a compreensão da memória humana e seu funcionamento é fundamental para o Direito e, mais especificamente, para entender o papel da testemunha no processo penal. Tudo convida ao estudo multidisciplinar acerca da memória humana e como pode ser traiçoeira, produzindo falhas sabotadoras, tema específico desse estudo e sobre o qual se trata na sequência.

\section{MEMÓRIA E FALSAS MEMÓRIAS: ABORDAGEM MULTIDISCIPLINAR}

Para compreender as falsas memórias e sua influência no processo penal, é fundamental descrever, em maneira sucinta, o contexto do funcionamento da memória humana, trazendo suas características, limitações, a evidenciarem as possibilidades de construções complexas que resultam da trama entre a realidade vivenciada, a imaginação e as influências externas. Aqui, há multidisciplinariedade, pois o direito há de olhar para fora de seu horizonte costumeiro, apelando às ciências ditas do ser, nomeadamente medicina, psicologia e psiquiatria de corte fisiológico.

\subsection{MEMÓRIA}

Com base nos ensinamentos de Wilson (2011, p.21-36), a memória é um dos componentes da mente humana e como tal, não é um simples elemento, nem é apenas uma função ou uma habilidade. Ao contrário é um conjunto de subsistemas que se interligam e se propagam, influenciam e são influenciados por diversos elementos internos ou externos.

A memória, segundo Izquierdo (2011, p. 11) "[...] significa aquisição, formação, conservação e evocação de informações." A aquisição também é 
chamada de aprendizado, e só se grava aquilo que foi aprendido. Aduz também que a evocação é conhecida como recordação, lembrança, e só lembramos aquilo que gravamos, aquilo que foi aprendido.

Portanto, a memória é elemento essencial para a formação de cada indivíduo. É a partir daquilo que presenciamos, ouvimos, sentimos, gravamos e interpretamos que formamos nossa personalidade e nos comunicamos com o mundo. Todo o processo de formação do ego ou primeira pessoa, no sentido da tomada de autoconsciência, por parte do indivíduo, guia-se pela estrutura mnemônica. E sua abertura para os demais indivíduos, em reconhecimento ao alter, ou terceira pessoa, igualmente tem-na por guia.

Para além de elemento basal de formação da personalidade, Sternberg (2008, p.156) aduz que a memória é o meio pelo qual codificamos, armazenamos as informações e eventos passados para recuperá-las quando alguma situação do presente requerer aquelas informações ou aprendizados. Exalta-se, neste ponto, que a cada mínimo gesto orientado à adaptação do ser humano ao mundo, ele evoca o acervo de memória sobre quadros similares e realiza, dentre aquelas compreensões arquivadas como verdadeiro background, suas escolhas.

$\mathrm{Na}$ fisiologia do cérebro, de acordo com Izquierdo (2011, p.12), não há uma localização específica para o armazenamento das memórias. Há sim, um conjunto de ligações e conexões de circuitos e estruturas neurais que envolvem lobos temporais mediais, córtex pré-frontal, cerebelo, septo medial, entre outros que trabalham em prol da memória.

A memória, em sua complexidade, pode ser catalogada em tipos e classificações, conforme Wilson (2011,p.36-50), tudo como consequência de apresentar-se como conjunto de subsistemas que atua em diversas frentes, recebendo, armazenando e dando significados aos eventos. A título de exemplo, o tempo de armazenamento de informações, se curto ou duradouro, permite catalogála em sensorial, de curto prazo ou imediata e de longo prazo (WILSON, 2011, p.22$63)$. 
A memória também pode ser classificada: a) pelo tipo de informação: memórias semânticas (implícitas), episódicas (autobiográficas) e procedurais (vinculada às capacidades motoras e sensoriais); b) pela modalidade específica dos sentidos empenhados no registro da informação, como memória tátil, auditiva, olfativa, gustativa ou visual; c) pelas etapas do processo de evocação, em memórias explícitas (episódicas) ou implícitas (de procedimento); d) pela projeção temporal, em evocação ou reconhecimento, que são as memórias retrospectivas e prospectivas.

Todos esses tipos e classificações ao final se relacionam e compõem o conjunto de condições, formas ou sistemas de percepção, captação, filtragem e armazenamento das informações, transformando vivências em memória. $E$, na complexidade da mente humana, dos sistemas neurais e cerebrais e sua relação com a psiquê, vislumbra-se a experiência cotidiana das falhas de reconstituição de fatos e falsas memórias.

Para explicá-las, Mlodinow (2014, p.54-55) alude ao fato de que nenhum de nós pode reter na memória, em integralidade, a vasta quantidade de detalhes com os quais nos deparamos nos diversos momentos de nossas vidas. Por isso, nossos erros de memória possuem uma origem comum: todos são artefatos que a nossa mente usa para preencher as inevitáveis lacunas.

Este modelo teórico também sugere que tais artefatos incluem confiar em nossas expectativas, em nossos valores, de uma forma geral, em nossos conhecimentos prévios. São os vieses ou desvios cognitivos. "Como resultado, quando nossas expectativas, nossos valores e conhecimento prévio estão às turras com os acontecimentos reais, nosso cérebro pode ser enganado" (MLODINOW, 2014, p.55). Vale-se, no ponto, de Münsterberg, o qual publicou em 1905 importantes estudos acerca do funcionamento da memória, influenciando a evolução do respectivo conhecimento. Em suas pesquisas, descobriu que as pessoas têm uma boa lembrança dos aspectos principais dos eventos, porém, uma má lembrança dos detalhes. Quando, passado o evento, são instadas ao relato por terceiro, ou meramente trazem o fato à consciência, como lembrança, veem-se como que 
pressionadas pelos detalhes não lembrados. É aí que, mesmo as pessoas bemintencionadas, fazendo esforços para serem precisas, sem querer, preenchem as lacunas quanto aos detalhes inventando situações que liguem os espaços, de maneira a delinearem uma história completa. Por fim, as pessoas acreditam nas lembranças que inventaram, fixam o relato como correspondência ao quadro de mundo vivenciado, não conseguindo discernir entre 0 real e o que criaram (MLODINOW, 2014, p.59-68).

Em confirmação destas conclusões, no ano de 1932, o psicólogo cognitivo Bartlett divulgou estudo mostrando que expectativas pessoais influenciam na memória de um evento passado, apontando que a recordação é, na verdade, um processo de reconstrução que envolve esquemas mentais e o conhecimento prévio da pessoa. Neste sentido, apontou que a cultura da pessoa é elemento que afeta a lembrança (SENE; LOPES; ROSSINI, 2014, p.24).

A memória é, portanto, um sistema organizado em diversos subsistemas e que pode, em algum momento, enfrentar problemas ocasionados por doenças, danos a algum dos elementos dos sistemas ou dificuldades psíquicas que podem produzir erros ou distorções na preservação de eventos ou sua interpretação (MLLODINOW, 2014, p.56-71). Destaca-se que fatores ambientais, sociais, culturais e educacionais influenciam na retomada da memória verídica ou na criação de memórias fantasiosas ou distorcidas. Dentre as várias manifestações de falhas de memória, interessa aqui o estudo das falsas memórias.

\subsection{FALSAS MEMÓRIAS}

Por falsa memória compreende-se a lembrança de eventos que nunca aconteceram ou que ocorreram, mas de forma muito diversa daquela relatada. Trata-se então, segundo Mazzoni e Scoboria (2007, p.788) de qualquer instância na qual a memória é reportada para um evento ou componente de um evento que não tenha sido experimentado. Similares, Santos e Stein (2008, p. 415) definem falsas 
memórias como "um tipo de distorção mnemônica que consiste na recuperação de eventos que nunca ocorreram".

Quando ocorre um fato de natureza intensa, especialmente no caso de uma tragédia, Di Gesu (2010, p.111) explica que a pessoa que o presenciou, no curto prazo, recorda-o com riqueza de detalhes. Porém, o tempo colabora para que as pessoas esqueçam detalhes concretos e mantenham as lembranças dramáticas e, portanto, emocionais. As falsas memórias atam os pontos lacunosos. E integram-se no campo mnemônico. Afinal, para além de referir-se ao passado da pessoa, a memória "deve-se fazer acompanhar de um processo emocional de crença" (FERRATER MORA, 2004, p. 1.927, aludindo aos estudos de William James). A pessoa acredita no produto final do processo de recordação.

As pesquisas em torno das falsas memórias são muitas e diversas. Buscam contemplar os potenciais fatores que influenciam a memória ou o seu sistema de funcionamento e que provocam as memórias falsas. São aspectos que vão desde questões neurais até emocionais. Importa destacar que criar falsas memórias é também um processo natural do sistema que lança mão deste tipo de conduta para fins de proteção, defesa e equilíbrio mental. É parte das funções da memória: lembrar, esquecer e produzir falsas memórias (STEIN et al., 2010, p.27).

As falsas memórias podem ser espontâneas ou ainda serem fruto de influências externas. Stein e Neufeld (2001, p.180-181) explicam que as falsas memórias espontâneas ou autossugeridas se configuram como um processo interno do indivíduo, sendo parte do mecanismo de funcionamento da memória. Portanto, neste caso a distorção da memória acontece de forma endógena: a pessoa recupera em sua memória o significado e a essência do fato vivido e não a memória literal. Em geral, a perda de memória literal é gerada pela inserção de novas informações. Quando for solicitado à pessoa que lembre ou narre determinado evento armazenado em sua memória e a informação original é apenas de significado, o processo natural do sistema da memória é comparar com novas informações armazenadas, que complementam a memória original. A partir daí, a pessoa cria sem domínio do processo - uma nova história. E crê nela. 
Já as falsas memórias sugeridas ou exógenas são aquelas que sofrem influência externa e consistem em falsas informações que são incorporadas na memória original por outra pessoa ou por alguma situação do ambiente externo. "Nossa memória é suscetível à distorção mediante sugestões de informações posteriores aos eventos. Além disso, outras pessoas, suas percepções e interpretações podem influenciar a forma como recordamos dos fatos" (STEIN et al, 2010, p. 26). Portanto, as falsas memórias sugeridas não são intencionais, mas frutos de uma percepção diversa acerca da mesma situação, por parte de terceiro. Quando relatada pelo terceiro àquele que tem armazenado em sua memória um contexto da mesma situação, acaba por influenciá-lo, mudando seu quadro interpretativo acerca daquele acontecimento.

No quadro dos fatores exógenos, Mlodinow (2014, p.72) explica que os seres humanos são muito suscetíveis as falsas memórias. Qualquer pessoa, com ou sem intenção, através de um simples comentário casual, pode acionar o sistema neural da outra pessoa a receber, armazenar e associar o relato a alguma outra situação já presente em sua memória. Assim, mais tarde, quando for lembrar de um evento verdadeiro, já terá esta informação falsa agregada como verdadeira em sua história original.

Entretanto, o mesmo autor assinala que, mesmo quando as memórias são totalmente fabricadas, elas, de um modo geral, se baseiam em uma verdade (2014, p.73). Os detalhes que foram inventados advêm de um universo subliminar da mente (não guarda correspondência com o clássico id ou inconsciente freudiano), de todo um sistema de experiências sensoriais e psicológicas do corpo humano, e das expectativas e convicções criadas a partir destas experiências. Explica que "o desafio enfrentado pela mente, e que corresponde ao inconsciente, é ser capaz de filtrar este inventário de dados a fim de reter as partes que realmente nos interessam" (MLODINOW, 2014, p. 57).

Importa destacar que falsas memórias são diferentes de mentiras ou formas de tentar ludibriar alguém. São, sim, fruto de fatos armazenados na memória e que, quando relembrados, associam fatos diferentes ou partes de uma situação 
vivenciada com outras criadas pela mente de forma inconsciente e/ou sugeridos a partir dos fatores exógenos elencados. O agente das falsas memórias acredita fielmente que aquilo que está narrando é a verdade vivenciada (SANTOS; STEIN, 2008, p.415-428).

Destacam-se as emoções como fonte de falsas informações Santos e Stein (2008, p.415-428), de modo que as áreas psicossanitária e jurídica têm dado especial atenção a este aspecto. Estudos realizados nas duas últimas décadas revelam que algumas técnicas psicoterapêuticas, utilizadas para recuperar memórias emocionas da infância, resultaram em evidências de que as emoções podem produzir lembranças de eventos que na realidade não aconteceram. É o caso de violência sexual sofrida na infância. Estas falsas memórias, induzidas pelas emoções, podem ser fruto de alguma sugestão ou de autossugestão, criando uma história completa ou apenas parte dela.

Os estudos neurocientíficos, além de avançarem no entendimento de como funciona a mente humana, suas interligações e influência de cada campo neural nas atividades mentais, desenhando os elementos condutores das falsas memórias, têm também avançado para demonstrações que "duvidam" da capacidade humana de conscientemente lembrar daquilo que viu, ouviu ou testemunhou, sem a influência dos processos neurais.

Note-se que o avanço das neurociências, sobretudo através de tecnologias como a ressonância magnética, espraia-se para outras sugestões incômodas. Além do peso da desconfiança sobre a credibilidade dos registros mnemônicos, a própria liberdade de decisão humana encontra-se em xeque. Recorde-se, por exemplo, a alusão de Crespo (2013, p.25-26) aos estudos que defendem as ações humanas como não guiadas por uma vontade consciente, mas sim por processos inconscientes, não havendo espaço para o livre arbítrio. Nossas ações estariam determinadas por estados imediatamente anteriores de nosso cérebro. Lado outro, a liberdade de vontade é sempre permeada pelo acervo de memória. Como explica Kahneman (2012, p. 186), "o indivíduo tende a orientar as suas tomadas de decisão 
pelo grau de probabilidade e de similaridade, com as grandezas comparadas e evocadas da memória."

A incômoda revelação das falsas memórias está cimentada. Oliver Sacks (2015, p.108), renomado neurologista, afirmava que quando uma história ou uma memória falsa é construída, acompanhada por imagens sensoriais vívidas e emoção forte, o ser humano pode não ser apto para distinguir o verdadeiro do falso, pode não haver um recurso interno, psicológico e nem algum modo neurológico externo que consiga fazer essa distinção. Enfim, construir histórias como recurso para complementação de lacunas na lembrança é um processo natural da memória humana, sem necessariamente ter base em uma realidade vivenciada.

Segundo Sacks (2015, p. 108-109), os correlatos fisiológicos desse tipo de memória podem ser examinados com técnicas de imagem funcional do cérebro - de novo a ressonância magnética -, as quais mostrarão que memórias vívidas produzem uma ativação cerebral praticamente idêntica, quer a memória seja baseada em experiência, quer construída internamente. "Ao que parece, a mente ou o cérebro não possui um mecanismo para assegurar a verdade, ou pelo menos o caráter verídico das nossas recordações".

O sistema da memória humana, portanto, é construído como um mecanismo que prioriza maneiras de garantir uma segura e protegida adaptação do indivíduo e seus quadros de consciência ao entorno de vida. Como tal, processa, muitas vezes sem consciência ou intenção, uma nova, diferente ou distorcida história, quando é instado a recordar ou narrar um evento. Assim, a falsa memória pode interferir diretamente no cotidiano do sujeito ou em outras situações sociais, como no campo dos processos judiciais, onde o relato de fatos passados é usualmente fundamental para levar as atividades jurisdicionais a bom termo. 


\section{FALSAS MEMÓRIAS NA PROVA TESTEMUNHAL DO PROCESSO PENAL}

A prova testemunhal, como já demonstrado, é um meio de prova importante para o Processo Penal e, em muitos casos, a única prova possível. Porém, o ser humano tem condições de funcionamento da sua memória que podem afetar a legitimidade de uma narrativa testemunhal, como a falsa memória, característica reconhecidamente necessária à função da memória humana na proteção da adaptação consciente do indivíduo ao mundo. Este é um tema recente, em que os estudos ainda buscam delinear compreensão e perspectivas sobre como e porque ocorrem, mas já se reconhece sua importância para o Direito Penal e a justiça processual penal.

As testemunhas, como repetidamente já se disse, são meios de prova fundamentais na maioria dos casos penais e muitos processos são exclusivamente embasados neste meio probatório. Baldasso e Ávila (2018, p.374) afirmam que, independentemente do delito cometido, e da forma como foram tomadas as declarações das testemunhas, a situação com a qual o magistrado se depara, na maioria dos casos, é a de que o processo penal está instruído basicamente com a prova oral. Ainda que alguns crimes, por características próprias, suscitem importante peso para a prova documental, como sonegações fiscais e previdenciárias, delitos funcionais e licitatórios, ou outros concitem prova material com submissão à perícia (evocando-se, aqui, a velha noção de corpo de delito e o art. 158, CPP), também neles a prova oral efetivamente aparece para, no mínimo, complementar aspectos imprescindíveis à adequada jurisdição.

A prova testemunhal vem sendo há séculos posta em dúvida. Baldasso e Ávila (2018, p.373) citam texto de Farinacci, de 1617, em que interpelava a condição da memória da testemunha acerca do evento. Percepções como esta, que duvidam da veracidade da prova testemunhal, indicam que falsas memórias vêm sendo identificada empiricamente há vários anos, não como desconfiança com peso sobre a testemunha, mas sobre sua memória. 
A temática tornou-se de tal forma relevante para o direito que o Ministério da Justiça desenvolveu e financiou o Diagnóstico Nacional de Práticas de Entrevistas Forenses e Reconhecimento Pessoal com o fim de desenvolver pesquisa científica multidisciplinar buscando apurar os elementos que afetam a confiabilidade da prova testemunhal. Tudo a envolver desde a compreensão do funcionamento da memória até a forma como as testemunhas são questionadas sobre suas memórias (BRASIL, 2015, p.17).

Em estudo conduzido por Baldasso e Ávila (2018, p.377-383, passim), adotando como referências acórdãos do Tribunal de Justiça do Rio Grande do Sul, levantaram-se entre 2004 e 2017, 437 julgados em que depoimentos com falsas memórias foram objeto de discussão. Desses 437 acórdãos, 90,16\% foram de Apelação Crime. Os demais estavam divididos em Embargos de Declaração (2,52\%), Embargos Infringentes e de Nulidade (2,29\%), Habeas Corpus $(1,60 \%)$, Recurso em Sentido Estrito (1,14\%), Revisão Criminal (1,14\%) e Recurso Especial e/ou Extraordinário (1,14\%). Com relação aos tipos penais, o levantamento realizado indicou o seguinte universo: estupro de vulnerável $(47,14 \%)$, roubo majorado $(17,39 \%)$, atentado violento ao pudor $(15,10 \%)$, estupro (5,95\%). Pelo bem jurídico com critério de classificação, crimes contra a dignidade sexual $(68,88 \%)$, crimes contra o patrimônio $(23,11 \%)$, crimes contra a vida $(1,14 \%)$, os crimes previstos em leis especiais (1,60\%), e os acórdãos sem classificação do tipo penal $(5,26 \%)$. Os autores assinalaram que, conquanto recorrente a proposição de discussão sobre a incidência de falsas memórias, escasso foi o impacto prático dos debates respectivos.

A preocupação do Ministério da Justiça (BRASIL, 2015, p.17) em estimular os estudos científicos e avaliar a influência das falsas memórias nos processos penais, bem como os resultados do estudo de Baldasso e Ávila (2018, p.371-407), apontam para alguns elementos importantes: a preocupação e interesse da justiça brasileira em identificar a relevância desta temática na realidade jurídica brasileira e na qualidade dos julgamentos; a constatação de número significativo de feitos em que invocações de falsa memória nos processos penais brasileiros podem ter 
conduzido as conclusões do julgado; a importância de equipe multidisciplinar, especialmente da psicologia aplicada ao testemunho, na condução da produção da prova nos processos judiciais, bem como o valor destes aspectos no julgamento justo e equânime.

É necessário, portanto, rever as práticas jurídicas, revisar a própria legislação e, principalmente, aprofundar o conhecimento acerca do tema, buscando analisar as possibilidades efetivas de neutralizar o problema no âmbito processual penal.

\subsection{FATORES INTENSIFICADORES DAS FALSAS MEMÓRIAS NO PROCESSO PENAL E POSSÍVEIS VIAS DE NEUTRALIZAÇÃO}

Um conjunto de fatores instam o desenvolvimento das falsas memórias. Avultam, dentre eles, a passagem do tempo e o procedimento de evocação da recordação.

O elemento temporal tem grande influência nas narrativas com falsa memória. Em adultos, em geral, as falsas memórias em situações forenses foram detectadas quando o testemunho é realizado semanas, meses ou anos após a ocorrência do evento. (STEIN; NEUFELD, 2001, p.184-185). A título de exemplo, em roubos, taxas de identificação de $71,43 \%$ deram-se em até um dia após o crime; já a passagem de tempo entre 7 e 34 dias derrubou-a para 33,33\%, e finalmente para $14,29 \%$, com mais de 34 dias, segundo estudo conduzido por Tollestrup, Turtle e Yuille (apud ÁVILA, 2013, p. 130).

Lado outro, a durabilidade da falsa memória pode dar-se pelo mesmo período cronológico que a memória original, ou seja, pode não se desgastar com a repetição da lembrança e ainda pode se intensificar, dado que a recordação solidifica mais o armazenamento pela memória (STEIN; NEUFELD, 2001, p.184). Afinal, a repetição consolida a narrativa criada pelo cérebro para preenchimento de hiatos nas impressões sensoriais associadas à vivência. 
Para neutralizar a influência do transcurso de tempo, como propulsor de falsas memórias, uma das alternativas sugeridas e utilizadas é a realização de diversas entrevistas com a mesma testemunha. Busca-se detectar, em algum momento, contradições na narrativa. A repetição de entrevistas poderia instar, ainda, a recordação de aspectos da história original, a partir da evocação reiterada da respectiva memória (STEIN; NEUFELD, 2001, p.183-185).

É duvidoso que este método seja consistente. Afinal, a retomada da narrativa, no processo comunicativo, retroalimenta o acervo mental fixado quanto ao evento e, mais das vezes, altera-o. Tomando por objeto de estudo a confecção de um acordo comercial, no qual as partes avançam e recuam na negociação no período de alguns dias, Leonard Mlodinow (2014, p.53) afirma que "na construção da memória, há o que você disse, mas também há o que comunicou, o que os outros participantes do processo interpretaram como sua mensagem, e finalmente, o que eles lembram dessas interpretações". É por este motivo que as pessoas costumam discordar radicalmente a respeito de suas lembranças de tal evento.

Afirma Mlodnow, ainda, que é pela mesma razão citada anteriormente que é comum, no universo da advocacia, adotar-se o expediente de tomar notas acerca de conversas importantes. Arremata que, "embora isso não elimine o potencial de lapsos de memória, sem dúvida o reduz" (2014, p. 53).

Aqui, de fato, aparece um método capaz de neutralizar falsas memórias, conduzido pelo próprio portador das lembranças. O sujeito, ao registrar as impressões vívidas do fato a ser futuramente recordado, quase que simultaneamente à experiência, fixa os contornos obtidos pelas impressões sensoriais imediatamente colocadas em contato com o fenômeno. A adição de elementos futuros, em construção típica de falsa memória, pode ser facilmente detectada pela comparação com os registros originais.

Evidentemente, não há um hábito de realização de similares registros, mediante anotações escritas de impressões pessoais, por parte de testemunhas que, acidentalmente, presenciam casos com contornos penais, no cotidiano de suas vidas. Raramente alguém chegará em casa e fará um registro escrito ad perpetuam 
rei memoriam. Porém, relatos contemporâneos ao evento acabam por serem fixados nas ferramentas de comunicação largamente difundidas a partir da sociedade em rede virtual. Por exemplo, a vívida narrativa do fato, pela testemunha, a terceiros, com muita probabilidade, pode ter sido feita mediante texto ou áudio em redes sociais (whatsapp, facebook, até eventuais registros fotográficos, por instagram, emails). Estas comunicações, armazenadas em arquivos, remanescem disponíveis, como a substituir o hábito, que em épocas anteriores foi modismo, de registrar o cotidiano da vida em diários (os quais, também, fariam as vezes das anotações de advogados, referidas por Mlodnow...).

A justiça criminal tem, nestes registros, úteis ferramentas para recognição fática capaz de minimizar falsas memórias. Os meios são vários. Passam pela orientação à testemunha para que verifique seus arquivos pessoais, contemporâneos ao evento. Eventualmente, e respeitado o acervo de direitos e garantias individuais, podem ocorrer pelo acesso determinado por ordem judicial (cuide-se que, de princípio, a quebra de privacidade ou intimidade, direitos fundamentais do art. $5^{\circ}, \mathrm{X}$ e XII, CR, por ordem judicial, tem no sujeito ativo do crime seu destinatário, não na testemunha). Até mesmo a busca e apreensão de equipamento eletrônico pode ter este escopo, à vista do art. $240,1^{\circ}$, alíneas e (primeira parte) e h, CPP.

Já por parte dos agentes do sistema penal - polícia ostensiva, técnica e de investigação - a realização de anotações sobre as imediatas impressões do evento deve ser padrão. São inúmeros os casos em que policiais militares não se recordam da ocorrência ou adicionam à narrativa aspectos coligados pelo mecanismo das falsas memórias, tudo por força da passagem do tempo. A realização de anotações contemporâneas à ocorrência - como praxe de trabalho diuturna - minimizaria imensamente estes defeitos nas narrativas dos responsáveis pelo atendimento e apuração inicial do caso penal.

Outro fator influenciador nas falsas memórias é o procedimento de evocação da recordação. Esta situação é bastante visível no meio de prova do reconhecimento pessoal do sujeito ativo do delito, bem estudado por Fonseca (2017, p.58). O 
Diagnóstico Nacional de Práticas de Entrevistas Forenses e Reconhecimento Pessoal (BRASIL, 2015, p.69) revelou que há maior cuidado quanto à adoção dos parâmetros codificados no art. 226 do CPP para realização do reconhecimento pessoal na etapa judicial, em regra durante a audiência, quando comparado ao reconhecimento procedido na etapa de investigação pré-processual. No entanto, a experiência forense costuma ser informal. É comum que apenas se pergunte à vítima ou testemunhas se reconhecem a pessoa do réu, usualmente presente ao ato. Neste caso, o procedimento formal de reconhecimento é substituído por prática em que o juízo ou a parte, quando da pergunta, aponta diretamente ao imputado como alvo do reconhecimento. O gesto de apontamento pode instar falsa memória.

$\mathrm{Na}$ fase policial, são comuns situações em que apenas uma foto é mostrada para que se confirme ou não a identidade. Esta prática é considerada pela psicologia do testemunho muito sujeita a erros. Raramente existe a estrutura do chamado vidro técnico, através do qual o reconhecedor visualiza um conjunto de pessoas com características similares, dentre as quais está aquela sob suspeita. $O$ próprio perfilamento de pessoas com características físicas semelhantes, lado a lado, é usualmente desrespeitado (art. 226, II) Conquanto não haja previsão legal para o reconhecimento fotográfico, ele é realizado (BRASIL, 2015, p.69).

Tais práticas, em regra, não encerram nulidade, segundo a iterativa orientação da jurisprudência. Porém, os julgados não se atêm ao eventual problema de que a mecânica procedimental sirva para concitar falsas memórias, ou no mínimo aporte elemento aditivo à recordação.

Enfim, a constatação e neutralização de falsas memórias exige um conjunto de esforços aos quais o aparelho de justiça somente agora passa a atentar - até porque, a consolidação da existência do fenômeno firma-se com o avanço da neurociência e psicologia cognitiva. Lopes Jr. e Di Gesu (2007, p.108-109) trazem algumas sugestões de melhorias nos procedimentos do processo para fins de evitar ou perceber falsas memórias, reconhecendo que não há soluções simples para problemas complexos: sugerem que a colheita de provas seja realizada em um prazo razoável, objetivando diminuir a influência do tempo que participa diretamente 
na produção de muitas falsas memórias; destacam a necessidade de adoção de técnicas de interrogatório e a entrevista cognitiva, que permitem a obtenção de informações quantitativa e qualitativamente superiores às das entrevistas tradicionais, altamente sugestivas e ainda apontam para a eficiência da gravação das entrevistas realizadas na fase pré-processual, principalmente as realizadas por assistentes sociais e psicólogos, pois, permite ao juiz o acesso a um completo registro eletrônico da entrevista.

Acrescentaríamos os já mencionados registros policiais escritos, adicionando a necessidade de filmagem de abordagens e ocorrências policiais, bem como o acesso ao acervo de arquivos de comunicação do responsável pelo relato, a partir - como regra -, de iniciativa da própria testemunha.

Todos esses elementos trazem luz ao tema e permitem comparar as práticas forenses, as normas existentes e as possibilidades de revisão, visando a melhora do sistema.

\subsection{CÓDIGO DE PROCESSO PENAL E AS FALSAS MEMÓRIAS}

Alguns dispositivos do Código de Processo Penal (CPP) têm elementos que viabilizam construir proteção contra falsas memórias. Colacionam-se, v.g., os arts. 204, 17, CPP. Outros, pela maneira como observados na praxis, podem intensificar a respectiva ocorrência, como os arts. 210, 212 e 226.

O já assinalado parágrafo único do art. 204. Vale transcrevê-lo: "Art. 204. O depoimento será prestado oralmente, não sendo permitido à testemunha trazê-lo por escrito. Parágrafo único. Não será vedada à testemunha, entretanto, breve consulta a apontamentos.

Como se observa, o parágrafo único delibera acerca da possibilidade de a testemunha lançar mão brevemente de apontamentos escritos ao narrar os fatos de interesse no processo. Em tese, o procedimento permitiria facilitar a lembrança fidedigna do evento, sem que haja garantias, já que a memória, quando do registro 
dos apontamentos pela testemunha, já pode estar contaminada (BRASIL, 2015, p.21), sobretudo pela ausência de contemporaneidade entre o evento e a anotação.

No caso do afastamento das testemunhas e do réu, o art. 17 do CPP aduz que, se o juiz verificar que a presença do réu causará humilhação, temor ou sério constrangimento à testemunha ou ao ofendido, de maneira que prejudique a veracidade do depoimento, poderá fazer a inquirição por videoconferência e, somente na impossibilidade dessa forma, determinará a retirada do réu, dando prosseguimento na inquirição, com a presença do seu defensor. Não se trata, propriamente, de mecânica voltada a evitar falsa memória. Todavia, certamente exonera o relato de mais um fator externo de pressão, capaz de contaminar o discurso testemunhal, i.é, a maneira como emprega palavras, enquanto signos linguísticos, para transmitir o registro mnemônico do tema de prova.

Com relação ao afastamento excepcional do réu quanto às testemunhas, antes dos seus depoimentos, este é um cuidado observado pelo judiciário brasileiro, embora o uso da videoconferência, como método, seja pouco utilizado.

O que não convém é que, em nome do temor de aproximar a testemunha do réu, limite-se $o$ depoimento destas à investigação, convocando-se preponderantemente autoridades de investigação e polícia ostensiva para os relatos em juízo. Este panorama reduz em muito o potencial de eficiência dos meios de prova no Processo Penal. (BRASIL, 2015, p.57).

Malatesta (2004, p.55) afirmava que a tranquilidade do depoente é um elemento fundamental para fomentar um depoimento verídico. Neste sentido, a exposição da testemunha a outras testemunhas ou ao réu aumenta substancialmente a possibilidade de sugestão e, portanto, de falsa memória. Ao contrário, nos depoimentos colhidos por entrevista técnica, a aproximação entre entrevistado e entrevistador cria vínculo de confiança (BRASIL, 2015, p.67), facilitando a exteriorização do registro mnemônico.

Já a inobservância das fórmulas legais, de modo estreito, pode instar falsas memórias. 
O art. 210 do CPP trata das condições em que o depoimento das testemunhas é realizado, expondo que cada testemunha será inquirida de maneira que as outras testemunhas não saibam e nem ouçam os depoimentos destas, devendo o magistrado adverti-las das penas cominadas ao falso testemunho. $O$ parágrafo único deste mesmo artigo afirma que antes do início da audiência e durante a sua realização, haverá espaços reservados separadamente para garantir a incomunicabilidade das testemunhas. Este cuidado, ao isolar o relato testemunhal, acaba prevenindo a contaminação do registro mnemônico em relação ao fator externo à memória da testemunha relativo às perspectivas das outras testemunhas.

Sobre este ponto, a pesquisa realizada pelo Ministério da Justiça aponta que as formas previstas no art. 210 do CPP não são, inúmeras vezes, efetivadas na prática jurídica. Embora não haja registro de testemunhas ouvidas ao mesmo tempo, é comum o descuido relativo à incomunicabilidade das testemunhas, antes de serem chamadas à audiência. Na maioria dos casos, elas ficam juntas em corredores, ocasião em que podem trocar impressões sobre os fatos, sem qualquer fiscalização. $O$ pouco de cautela que se tem em alguns casos é o distanciamento das testemunhas e do réu ou, das testemunhas de acusação daquelas de defesa (BRASIL, 2015, p.67).

O CPP, em seu artigo 212, traça a forma como a arguição das testemunhas deve ser realizada. Prevê que as perguntas serão formuladas pelas partes diretamente à testemunha, não sendo permitidas pelo juiz aquelas que puderem induzir a resposta, não tiverem relação com a causa ou ainda, importarem na repetição de outra já respondida (BRASIL, 1941, p. s/n).

Na prática, o estudo realizado pelo Ministério da Justiça aponta falhas na capacidade dos profissionais de organizar adequadamente perguntas, porquanto muitas vezes repetitivas ou indutivas. Também, aponta-se interferência do juiz para além dos pontos não esclarecidos, que são os únicos em que deveria arguir, segundo o modelo acusatório mitigado por atividade residual judicial de investigação quanto a aspectos dubitativos da matéria de fato. Muitos juízes ainda realizam as perguntas iniciais, ainda antes de o Ministério Público e a Defesa realizarem essa 
tarefa, conquanto destinada primordialmente a eles. Muitos, ainda, filtram as perguntas, perseverando no superado modelo da repergunta judicial a partir da pergunta formulada pela parte. Observou o estudo que as perguntas do juiz se mantêm e para além disso, são indutivas e fechadas, diminuindo as possibilidades de recuperação de informações, pela memória da testemunha, que sejam confiáveis e com qualidade (BRASIL, 2015, p.67).

Pontualmente, exalta-se a existência de método de condução das perguntas minimizador de falsas memórias e redutor do poder de sugestão do inquirente. Trata-se da entrevista cognitiva, composta dos seguintes passos: a) constituição de relação inicial amistosa em ambiente acolhedor; b) instância ao entrevistado para que se situe no contexto original do fato recordado; c) a partir daí, obtenção da narrativa livre acerca dele; d) só após, sobrevém o questionamento mediante perguntas; e) fechamento da inquirição, mediante resumo dos fatos comunicados e manutenção, em aberto, do processo comunicativo (tudo cf. ÁVILA, 2013, pp. 140143).

O art. 226 trata do reconhecimento, meio de prova já tratado no item anterior, utilizados tanto na fase pré-processual, como processual (BRASIL, 1941, p. $\mathrm{s} / \mathrm{n}$ ). Este momento tem relação direta com a memória, pois como explica Cordero (2000, p. 106) "[...] uma pessoa é levada a perceber alguma coisa e, recordando o que havia percebido em um determinado contexto, compara as duas experiências". É instigada a relatar se a pessoa ou objeto se coadunam. A recuperação da memória é então invocada, podendo sofrer influências endógenas ou exógenas, reportando uma falsa memória. Como já descrito por Santos e Stein (2008, p.415428) as emoções afetam a memória e este é um momento em que referido fator pode ter influência no processo psicológico de recuperação da memória. 0 apontamento da pessoa a ser identificada, qualificada como réu, no ato da audiência, por autoridade judicial, é praxe que pode premir a formação de falsa memória, como sustentado no item anterior. Trata-se de modo inadequado de evocar as vivências. Potencializa eventual sugestionabilidade, cuja recorrência deve 
ser evitada pelos integrantes do sistema penal, através de treinamento (ÁVILA, 2013, p.160).

Portanto, no contexto atual, algumas práticas policiais e forenses acabam por colaborar para o desenvolvimento de falsas memórias. De outra banda, o tema deve ser exaltado para capacitação e adequação da estrutura do sistema penal voltada à identificação de testemunhos com falsas memórias.

\section{CONSIDERAÇÕES FINAIS}

A compreensão do fenômeno das falsas memórias, intrínsecas ao modo como os registros mnemônicos são armazenados na mente, é objeto de preocupação necessária do aparelho de justiça criminal. É preciso identificar o impacto do fenômeno no processo de recognição fática, procedido durante a instrução.

Certo descompasso entre as formas legais e as práticas jurídicas apontam para o eventual incremento das falsas memoriais a partir da praxis destinada à recolha da prova. Há necessidade de buscar mudanças efetivas relacionadas: a) à observância das respectivas formas; b) à integração do tema das falsas memórias nos relatos testemunhais, ao debate sobre o prejuízo advindo de atos processuais nulos, na perspectiva da adequada observação do princípio pas de nullitè sans grief; c) à adoção de práticas interdisciplinares no processo penal, ligados, v.g., à psicologia do testemunho, pouco utilizadas e estimuladas no campo do Direito e na área jurídica, exceto setores pontuais, como os relatos de crianças vítimas de delitos sexuais.

Cabe, portanto, ao universo dos operadores e estudiosos do direito processual penal associar-se a outras disciplinas e ciências, como as neurociências, a psicologia e especificamente a psicologia do testemunho, para buscar medidas e soluções que possam efetivamente diminuir o efeito das falsas memórias no 
processo penal, colaborando diretamente para decisões mais precisas na solução das matérias de fato subjacentes a cada caso penal.

\section{REFERÊNCIAS}

AQUINO, José Carlos. G. Xavier. A Prova Testemunhal no Processo Penal Brasileiro. 3. ed. São Paulo: Saraiva, 1995.

ÁVILA, Gustavo Noronha de. Falsas memórias e sistema penal: a prova testemunhal em xeque. Rio de Janeiro: Lumen Juris, 2013.

BADARÓ, Gustavo Henrique Righi Ivahy. Ônus da prova no processo penal. São Paulo: RT, 2003.

BALDASSO, Flaviane; ÁVILA, Gustavo Noronha de. A Repercussão do Fenômeno das Falsas Memórias na Prova Testemunhal: uma análise a partir dos Julgados do Tribunal de Justiça do Rio Grande do Sul. Revista Brasileira de Direito Processual Penal (RBDPP), v. 4, p. 317-409, 2018. Disponível em: <http://index.pkp.sfu.ca/index.php/record/view/691295>. Acesso em: 6 out. 2018.

BRASIL. Avanços científicos em Psicologia do Testemunho aplicados ao Reconhecimento Pessoal e aos Depoimentos Forenses. Ministério da Justiça, Secretaria de Assuntos Legislativos. Brasília: Ministério da Justiça, Secretaria de Assuntos Legislativos (SAL); Ipea, 2015. 104p. Disponível em: <http://pensando.mj.gov.br/wp-content/uploads/2016/02/PoD_59_Lilian_web-1.pdf>. Acesso em: 5 out. 2018.

. Presidência da República. Código de Processo Penal, 1941. Disponível em: <http://www.planalto.gov.br/ccivil_03/decreto-lei/Del3689Compilado.htm>. Acesso em: 08 out. 2018.

CAPEZ, Fernando. Curso de Processo Penal. 23a. ed. São Paulo: Saraiva, 2016.

CORDERO, Franco. Procedimiento Penal. v. II. (trad. Jorge Guerrero). Bogotá: Temis, 2000.

CRESPO, Eduardo Demetrio. Compatibilismo Humanista: Uma Propuesta de Conciliación Entre Neurociencias Y Derecho Penal. In: CRESPO, E. D.; CALATAYUD, M. M; Neurociencias y Derecho Penal Nuevas perspectivas em el âmbito de la culpabilidad y tratamiento jurídico-penal de la peligrosidad. Montevidéu, Buenos Aires, BdF, 2013. 
DI GESU, Cristina Carla. Prova penal e falsas memórias. 2.ed. ampl. e rev. Porto Alegre: Livraria do Advogado Editora, 2014.

Prova penal e falsas memórias. Rio de Janeiro: Lumen Juris, 2010.

DIAS, Jorge de Figueiredo. Direito Processual Penal. Coimbra Editora, 1974.

FEITOZA, Denilson. Direito Processual Penal. Niterói: Impetus, 2009.

FERRATER MORA, José. Dicionário de Filosofia. Tomo III. São Paulo: Loyola, 2004.

FONSECA, Caio Espindola. Processo Penal e Falsas Memórias: A Influência Das Distorções Da Mente Na Prova Testemunhal. Rio de Janeiro: 2017: 71 p. Monografia (Graduação) curso de Direito. Departamento de Direito da Pontifícia Universidade Católica do Rio de Janeiro - PUC-Rio, 2017.

GREGO FILHO, Vicente. Manual de Processo Penal. 10. ed. São Paulo: Saraiva, 2015.

IZQUIERDO, Ivan. Memória. 2. ed., revista e ampliada. Porto Alegre: Artmed, 2011.

KAHNEMAN, Daniel. Rápido e devagar: duas formas de pensar. Trad. Cássio de Arantes Leite. Rio de Janeiro: Objetiva, 2012.

LIMA, Marcellus. Polastri. Curso de Processo Penal. V. II. 3. ed. atual. de acordo com a reforma processual penal de 2008 (Leis 11.689 , 11.690 e 11.719) Rio de Janeiro: Lumen Juris, 2008.

LIMA, Renato Brasileiro. Manual de Processo Penal. Niterói: Impetus, 2011.

LOPES JR, Aury.; DI GESU, Cristina Carla. Falsas Memórias e Prova Testemunhal no Processo Penal: Em Busca da Redução de Danos. Revista de Estudos Criminais. Abr./Jun. de $2007 . \quad$ Disponível em: $<$ https://bdjur.tjdft.jus.br/xmlui/handle/123456789/10798?show=full>. Acesso em: 07 out. 2018.

LOPES JUNIOR, Aury. Direito Processual Penal. 13. ed., editora: Saraiva, 2015.

MALATESTA, Nicola. F. D. A lógica das provas em Matéria Criminal. Campinas: Bookseller, 2004, (Paolo Capitanio - Tradutor).

MAZZONI, G.; SCOBORIA, A. False memories. In: DURSO, F. T. et al.(edit.), Handbook of Applied Cognition 2. ed, 2007, p. 787-813. 
MLODINOW, Leonard. Subliminar: como o inconsciente influencia nossas vidas. Rio de Janeiro: Zahar, 2014 (Cláudio Carina - Tradutor).

MUÑOZ CONDE, Francisco. La búsqueda de la verdad en el proceso penal. 2. ed. Buenos Aires; Hammurabi, 2003.

ROSA, Alexandre .Moraes da. Variáveis ocultas e efeito borboleta na decisão penal. Conjur, 2014. Disponível em: <http://www.conjur.com.br/2014-mar-22/diario-classevariaveis-ocultas-efeito-borboleta-decisao-penal>. Acesso em: 5 jan. 2019.

SACKS, Oliver. O rio da consciência. São Paulo: Cia. Das Letras, 2017 (Laura Teixeira Motta - tradutora).

SAFRANSKI, Rüdiger. Heidegger, um mestre da Alemanha entre o bem e o mal. São Paulo: Geração, 2005.

SANTOS, Renato Favarin dos.; STEIN, Lilian M. A influência das emoções nas falsas memórias: uma revisão crítica. Psicologia USP, v. 19, n. 3, p. 415-434, 2008. Disponível em: <http://www.revistas.usp.br/psicousp/article/view/41971>. Acesso em: 6 out. 2018.

SENE, A. S.; LOPES, E. J.; ROSSINI, J. C. Falsas memórias e tempo de reação: estudo com o procedimento de palavras associadas. Psychologica,v. 57, p. 25-40, $2014 . \quad$ Disponível em: <http://impactumjournals.uc.pt/psychologica/article/view/2068>. Acesso em: 4 out. 2018.

STEIN, Lilian Milnitsky et al. Falsas memórias: fundamentos científicos e suas aplicações clínicas e jurídicas. Porto Alegre: Artmed, 2010.

STEIN, Lilian Milnitsky.; NEUFELD, Carmem Beatriz. Falsas Memórias: Porque lembramos de coisas que não aconteceram? Arquivos de Ciências da Saúde da UNIPAR, UMUARAMA, PR, v. 5, n.2, p. 179-185, 2001. Disponível em: $<$ http://revistas.unipar.br/index.php/saude/article/view/1124/987>. Acesso em: 2 out. 2018.

STERNBERG, Robert J. Psicologia Cognitiva. Porto Alegre: 4a. ed. Porto Alegre: Editora Artmed, 2008.

VOLK, Klaus. La verdad sobre la verdad y otros estudios. Buenos Aires: Ad Hoc, 2007.

WILSON, Barbara. A. Reabilitação da Memória. Integrando Teoria e Prática. Porto Alegre: Artmed, 2011. 